\title{
Chemical Synthesis of Polysaccharides III. A Synthetic Polysaccharide Having One Hydroxyl Group in Its Repeating Unit, 3,4-Dideoxy-(1 $\rightarrow 6)-\alpha$ - DL-threo-hexopyranan
}

\author{
Masahiko OKADA, Hiroshi Sumitomo, and Ken Ogasawara \\ Faculty of Agriculture, Nagoya University, \\ Chikusa, Nagoya 464, Japan
}

(Received July 4, 1983)

\begin{abstract}
A new DL-polysaccharide having a regiospecific hydroxyl group in its repeating unit (3,4-dideoxy-( $1 \rightarrow 6)$ - $\alpha$-DL-threo-hexopyranan) was synthesized from 3,4-dihydro- $2 H$-pyran-2carbaldehyde (acrolein dimer): A bicyclic acetal, 4(e)-benzyloxy-6,8-dioxabicyclo[3.2.1]octane (1), was prepared from the starting material via eight step reactions. The cationic ring-opening polymerization of 1 at $-60^{\circ} \mathrm{C}$ with antimony pentafluoride, antimony pentachloride, and trifluoromethanesulfonic acid as initiators afforded stereoregular polyacetals (2) of relatively low molecular weights $\left(M_{n}, 5800-8600\right)$. The subsequent removal of the protecting group of 2 with sodium in liquid ammonia gave a white fluffy polymer identified as 3,4-dideoxy-(1 $\rightarrow 6)-\alpha$-DL-threohexopyranan (3) by ${ }^{13} \mathrm{C}$ NMR spectroscopy. The synthetic polysaccharide melting at $136-150^{\circ} \mathrm{C}$ was soluble in methanol, dimethyl sulfoxide, and dimethylformamide, but insoluble in water and other common organic solvents. The water sorption behavior of $\mathbf{3}$ was examined at different relative humidities from 43 to $97 \%$, and compared with those of relevant natural and synthetic polysaccharides.
\end{abstract}

KEY WORDS Synthetic Polysaccharide / Ring-Opening Polymerization / Bicyclic Acetal / Water Sorption /

The chemical synthesis of stereoregular polysaccharides has been a subject of continuing interest, since the first stereospecific synthesis of a linear polysaccharide containing only $(1 \rightarrow 6)$-linked $\alpha$-Dglucopyranosyl residues was achieved by the ringopening polymerization of 1,6-anhydro-2,3,4-tri- $O$ methyl- $\beta$-D-glucopyranose. ${ }^{1}$ Synthetic polysaccharides of well-defined structure can be used as model substances to investigate the action pattern of enzymes, induction and reaction of antibodies, and the effect of structure on biological activity in the interaction of proteins, nucleic acids, and lipids with polyhydroxylic macromolecules. ${ }^{2}$ They should furnish a large variety of potentially useful materials with properties widely variable by appropriate chemical modification.

In this regard, we recently synthesized two deoxy-DL-polysaccharides $\quad(3,4$-dideoxy- $(1 \rightarrow 6)-\alpha$-DLerythro-hexopyranan ${ }^{3}$ and 4 -deoxy- $(1 \rightarrow 6)-\alpha$-DLxylo-hexopyranan ${ }^{4}$ ) starting from a noncarbohy- drate source, 3,4-dihydro-2 $H$-pyran-2-carbaldehyde (an acrolein dimer), via the cationic ring-opening polymerization of 6,8-dioxabicyclo[3.2.1]octane derivatives. This paper presents the chemical synthesis of a new (1 $\rightarrow 6)$-linked DL-polysaccharide (3) having regiospecifically one hydroxyl group in its repeating unit by the ring-opening polymerization of $4(e)$ benzyloxy-6,8-dioxabicyclo[3.2.1]octane (1,6-anhydro-2- $O$-benzyl-3,4-dideoxy- $\beta$-DL-threo-hexopyranose) (1) and the subsequent removal of the protecting group of the resulting polymer (2).

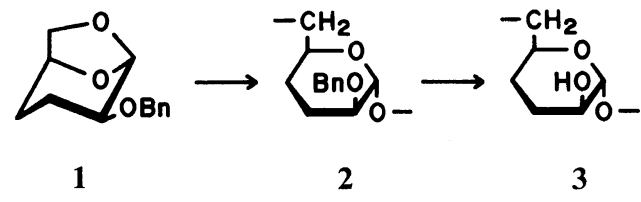

$\mathrm{Bn}:-\mathrm{CH}_{2} \mathrm{C}_{6} \mathrm{H}_{5}$ 


\section{EXPERIMENTAL}

4(e)-Benzyloxy-6,8-dioxabicyclo[3.2.1]octane (1) was synthesized from 3,4-dihydro- $2 \mathrm{H}$-pyran-2carbaldehyde (4) via eight step reactions as illustrated in Scheme I. The synthetic procedures for 4(a)-hydroxy-6,8-dioxabicyclo[3.2.1]octane (9) described by Brown et $a l .^{5-7}$ were employed with some modification.

\section{Preparation of 6,8-Dioxabicyclo[3.2.1]octan-4-one $(\mathbf{1 0})^{8}$}

Oxidation of 9 to the corresponding ketone $\mathbf{1 0}$ was achieved using ruthenium tetroxide ${ }^{9}$ as the oxidizing agent. An aqueous solution $(200 \mathrm{ml})$ of sodium periodate $(50 \mathrm{~g}, 230 \mathrm{mmol})$ was added dropwise at $0^{\circ} \mathrm{C}$ to a suspension of ruthenium dioxide dihydrate $(7.5 \mathrm{~g}, 33 \mathrm{mmol})$ in dichloromethane $(200 \mathrm{ml})$. Stirring was continued for one and a half hours until all the ruthenium dioxide dissolved. The organic layer was separated and filtered with a sintered glass filter to eliminate the insoluble materials. The filtrate was well shaken with an aqueous solution of sodium periodate to afford a yellow solution of ruthenium tetroxide in dichloromethane. The ruthenium tetroxide solution thus prepared was added dropwise to an ice-cooled solution of 9 in dichloromethane, and the mixture was stirred for further $10 \mathrm{~min}$. Excess ruthenium tetroxide was decomposed by adding a small amount of isopropyl alcohol. The ruthernium dioxide precipitated as a black fine powder was separated by filtration, and the filtrate was dried over anhydrous magnesium sulfate. Removal of the solvent by a rotary evaporator gave $\mathbf{1 0}$ as a transparent liquid. Yield, $61 \%$.

\section{Preparation of 4(e)-Hydroxy-6,8-dioxabicyclo- [3.2.1] Joctane $(\mathbf{1 1})^{8}$}

Sodium borohydride $(0.90 \mathrm{~g}, 24 \mathrm{mmol})$ was cautiously added in portions to a methanol solution $(30 \mathrm{ml})$ of $10(1.3 \mathrm{~g}, 10 \mathrm{mmol})$ at $-30^{\circ} \mathrm{C}$. After adding the reducing agent, the temperature of the reaction mixture was gradually raised to room temperature, and the reaction mixture was allowed to stand overnight. The solvent was removed by a rotary evaporator, and the resulting residue was dissolved in a $20 \%$ aqueous sodium hydroxide solution. The solution was extracted thoroughly with dichloromethane, and the extract was dried over anhydrous magnesium sulfate. Removal of the solvent under reduced pressure afforded $\mathbf{1 1}$ as a waxy material in $71 \%$ yield.

\section{Preparation of 4(e)-Benzyloxy-6,8-dioxabicyclo- [3.2.1]octane (1)}

Benzylation of $\mathbf{1 1}$ was carried out by the procedure previously described for the preparation of 4(a)-benzyloxy-6,8-dioxabicyclo[3.2.1] octane (12). ${ }^{3}$ The crude product was chromatographed (column, silica gel; eluent, $n$-hexane-ethyl acetate $(7: 3 \mathrm{vol})$. to provide 1 as a viscous oil. Yield, $90 \%$. The monomer was dried over calcium hydride and distilled before use. Bp, $78-81^{\circ} \mathrm{C} / 0.9 \mathrm{mmHg}$. Anal. Calcd for $\mathrm{C}_{13} \mathrm{H}_{16} \mathrm{O}_{3}: \mathrm{C}, 70.89 \% ; \mathrm{H}, 7.33 \%$. Found: $\mathrm{C}, 70.62 \% ; \mathrm{H}, 7.33 \% \cdot{ }^{13} \mathrm{C}$ NMR $\left(\mathrm{CDCl}_{3}\right.$, tetramethylsilane), $\delta 138.02$ phenyl (ipso), 128.10 phenyl (ortho), 127.40 phenyl (meta and para), $100.78 \mathrm{C}(5)$, $75.57 \mathrm{C}(4), 72.92 \mathrm{C}(1), 70.51$ benzyl, $68.52 \mathrm{C}(7)$, $27.82 \mathrm{C}(2)$, and $22.76 \mathrm{ppm} \mathrm{C}(3)$.

\section{Polymerization of 4(e)-Benzyloxy-6,8-dioxabi-} cyclo[3.2.1]octane (1)

Polymerization of $\mathbf{1}$ was carired out in dichloromethane at $-60^{\circ} \mathrm{C}$, using antimony pentafluoride, antimony pentachloride, and trifluoromethanesulfonic acid as the initiators. The polymerization and work-up procedures were similar to those described previously ${ }^{3}$

\section{Debenzylation of Poly(3(a)-benzyloxytetrahydro-} pyran-6,2-diyloxymethylene) (2)

The benzyl group of polymer 2 was removed by treating 2 with sodium in liquid ammonia. The detailed procedure was given in the previous paper. ${ }^{3}$

\section{Characterization}

${ }^{13} \mathrm{C}$ NMR spectra were recorded on a JEOL FX100 instrument operating at $25 \mathrm{MHz}$. Chloroform- $d$ and dimethyl sulfoxide- $d_{6}$ were used as solvents for the benzylated polymer 2 and the debenzylated polymer 3, respectively. Tetramethylsilane was employed as the internal reference. The number-average molecular weight of 2 was estimated by gel permeation chromatography (column, Shodex $80 \mathrm{M}, 1 \mathrm{~m}$; eluent, chloroform; polystyrene standard). The number-average molecular weight of 3 was determined by vapor pressure osmometry on solutions in dimethylformamide at $37^{\circ} \mathrm{C}$. Water sorption of $\mathbf{3}$ was measured at various relative hu- 
midities from 43 to $97 \%$ by the procedure reported in the previous paper ${ }^{3}$ and represented as the percent of weight increase based on dry samples.

\section{RESULTS AND DISCUSSION}

4(e)-Benzyloxy-6,8-dioxabicyclo[3.2.1]octane (1) was prepared from 3,4-dihydro-2 $H$-pyran-2-carbaldehyde through the eight reaction steps illustrated in Scheme 1. ${ }^{5-8}$ The stereochemical aspects of the reactions involved in the synthetic route leading to 4(a)-hydroxy-6,8-dioxabicyclo[3.2.1]octane (9) were discussed in detail in the previous paper. ${ }^{3}$ Oxidation of 9 with ruthenium tetroxide followed by column chromatographic purification gave the corresponding ketone (10) in a $61 \%$ yield. Attempted oxidation of 9 with dimethyl sulfoxide-acetic anhydride ${ }^{10}$ or dimethyl sulfide- $N$-chlorosuccinimide ${ }^{11}$ was unsuccessful. Reduction of $\mathbf{1 0}$ with sodium borohydride under carefully controlled conditions provided 4(e)-hydroxy6,8-dioxabicyclo[3.2.1]octane (11) contaminated with a small amount $(<7 \%)$ of the axial counterpart (9). It was difficult to eliminate the contaminant by column chromatography and so the reaction product as such was benzylated in dimethyl sulfoxide using sodium hydride and benzyl chloride. The resulting viscous oil was subjected to column chromatography and finally distilled under reduced pressure to afford $\mathbf{1}$ as a transparent viscous oil. The overall yield based on the starting material was approximately $6 \%$.

Polymerization of 1 was carried out in dichloromethane at $-60^{\circ} \mathrm{C}$. The results are presented in Table I. The molecular weights of the polymers estimated by gel permeation chromatography were relatively low. Polymer 2 was a white powdery material melting at $61-75^{\circ} \mathrm{C}$ and was soluble in a wide variety of solvents including carbon tetrachloride, benzene, chloroform, tetrahydrofuran, and dimethylformamide.

Figure 1 shows a typical ${ }^{13} \mathrm{C}$ NMR spectrum of the polymer 2 along with the signal assignments. The appearance of the acetal carbon signal at

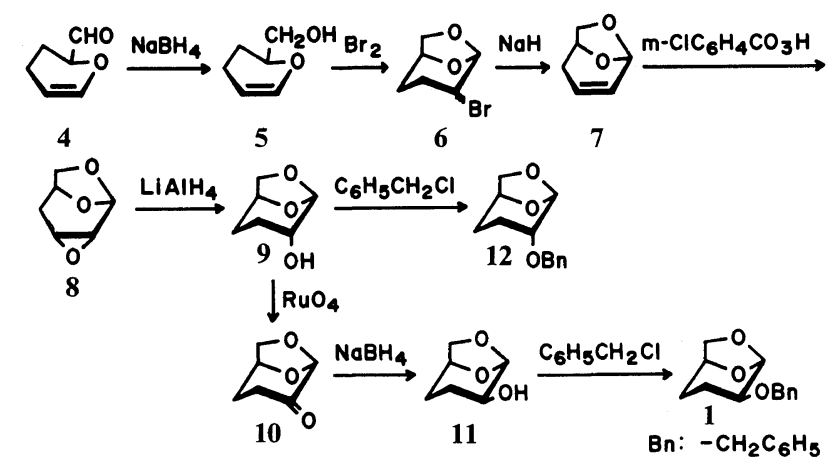

Scheme 1. Synthetic route of 4(e)-benzyloxy-6,8-dioxabicyclo[3.2.1]octane (1).

Table I. Polymerization of 4(e)-benzyloxy-6,8-dioxabicyclo[3.2.1]octane (1) ${ }^{\mathrm{a}}$

\begin{tabular}{|c|c|c|c|c|c|c|c|}
\hline \multirow{2}{*}{ Initiator } & \multirow{2}{*}{$\mathrm{mmol}$} & \multirow{2}{*}{$\frac{\text { Temp }}{{ }^{\circ} \mathrm{C}}$} & \multirow{2}{*}{$\frac{\text { Time }}{\text { day }}$} & \multirow{2}{*}{$\frac{\text { Yield }}{\%}$} & \multirow{2}{*}{$\begin{array}{c}M_{n}{ }^{\mathrm{b}} \\
\times 10^{-3}\end{array}$} & \multirow{2}{*}{$\begin{array}{c}M_{w}{ }^{\mathrm{b}} \\
\times 10^{-3}\end{array}$} & \multirow{2}{*}{$\frac{\alpha \text {-Content }}{\%}$} \\
\hline & & & & & & & \\
\hline $\mathrm{SbF}_{5}$ & 0.25 & -60 & 2 & 69 & 8.6 & 15.9 & $\sim 100$ \\
\hline $\mathrm{SbCl}_{5}$ & 0.25 & -60 & 2 & $84^{\mathrm{d}}$ & 6.2 & 12.8 & $\sim 100$ \\
\hline $\mathrm{CF}_{3} \mathrm{SO}_{3} \mathrm{H}$ & 0.25 & -60 & 7 & 44 & 5.8 & 8.8 & $\sim 100$ \\
\hline
\end{tabular}

a Monomer $5 \mathrm{mmol}$; solvent, $\mathrm{CH}_{2} \mathrm{Cl}_{2}, 1.0 \mathrm{ml}$.

b By gel-permeation chromatography (polystyrene standard).

c By ${ }^{13} \mathrm{C}$ NMR spectroscopy.

d Elemental analysis. Calcd for $\left(\mathrm{C}_{13} \mathrm{H}_{16} \mathrm{O}_{3}\right)_{n}$ : C, $70.89 \%$; H, 7.33\%. Found: C, $71.05 \%$; H, 7.38\%. 
$\delta 97.6 \mathrm{ppm}$ indicates that the polymer consists of a structural unit ( $\alpha$-form) in which the exocyclic acetal oxygen is oriented axially to the tetrahydropyran ring. As the expanded spectrum demonstrates, the acetal carbon signal d consists of a pair of peaks ( $\delta 97.9$ and $97.6 \mathrm{ppm}$ ) of different intensities. In addition, the signals $\mathrm{g}$ and $\mathrm{h}$, assignable to the exocyclic methylene carbon and the methine carbon adjacent to the ring oxygen, respectively, show shoulder in the lower field side. These signals are not due to the coexistence of any other structural units (for instance, the $\beta$-form should give rise to the acetal carbon signal at several ppm downfield compared with that for the $\alpha$-form) but to the diad placements of the D,L-enantiomeric monomeric units along the polymer chain. This point will be discussed later.

It is of interest to compare the polymerization reactivity of $\mathbf{1}$ with that of its axial counterpart 12. The difference in the spatial orientation of the benzyloxy substituent between these two monomers corresponds to that between 1,6-anhydro-2,3,4-tri$O$-benzyl- $\beta$-D-mannopyranose and 1,6-anhydro2,3,4-tri- $O$-benzyl- $\beta$-D-glucopyranose. Schuerch and his coworkers ${ }^{12-14}$ investigated the homopolymerization and copolymerization of these anhydro sugar derivatives, and disclosed that the mannose derivative was more reactive than the glucose derivative. In the present case, the equatorially substituted monomer $\mathbf{1}$ gave the polymer in a higher yield than did the axially substituted monomer 12 under identical reaction conditions. Furthermore, the copolymerization of an equimolar mixture of 1 and 12 afforded a copolymer composed of $86 \% 1$ and $14 \% 12$ (initiator, $\mathrm{SbF}_{5}$; solvent, $\mathrm{CH}_{2} \mathrm{Cl}_{2}$; temp, $-60^{\circ} \mathrm{C}$; yield, $18 \%$ ). These findings suggest, although qualitatively, that equatorial isomer $\mathbf{1}$ is more reactive than the axial isomer $\mathbf{1 2}$ in their polymerization. This is contrary to the expectation based on the thermodynamical consideration that the axially substituted monomer 12 yields an energetically favorable, equatorially substituted

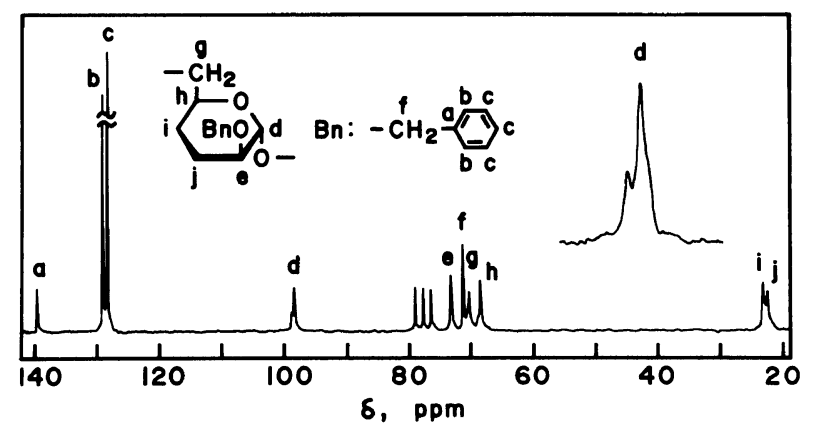

Figure 1. ${ }^{13} \mathrm{C}$ NMR spectrum of poly(3(a)-benzyloxytetrahydropyran-6,2-diyloxymethylene) (2): Solvent, $\mathrm{CDCl}_{3}$; temp, $50^{\circ} \mathrm{C} ; 25 \mathrm{MHz}$; internal reference, tetramethylsilane.

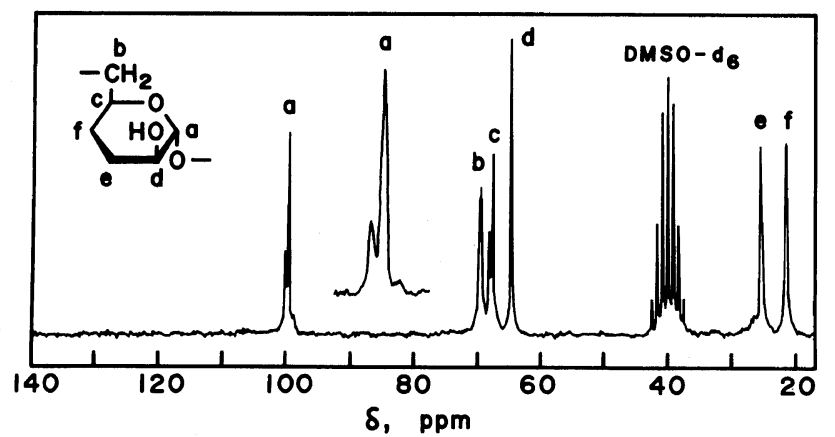

Figure 2. ${ }^{13} \mathrm{C}$ NMR spectrum of 3,4-dideoxy-(1 $\left.\rightarrow 6\right)-\alpha$-DL-threo-hexopyranan (3): Solvent, $\mathrm{CD}_{3} \mathrm{SOCD}_{3}$; temp, $70^{\circ} \mathrm{C} ; 25 \mathrm{MHz}$; internal reference, tetramethylsilane. 
polymer and hence its polymerizability should be higher than the equatorially substituted monomer 1. Therefore, the apparent higher reactivity of $\mathbf{1}$ is, at least partly, attributable to the less steric hindrance encountered when $\mathbf{1}$ approaches the active growing chain end, compared with the axially substituted monomer 12.

Debenzylation of polymer 2 by the conventional method using sodium in liquid ammonia proceeded smoothly to provide a polymer containing a free hydroxyl group per repeating unit. The ${ }^{13} \mathrm{C}$ NMR spectrum measured in dimethyl sulfoxide- $d_{6}$ is shown in Figure 2. The chemical shift data are compatible with the structure given in the figure $(\delta$ : a, 99.54 and $98.82 ;$ b, 68.83; c, 67.59 and 66.97; d, 64.13 ; e, 25.29; f, $21.40 \mathrm{ppm}$ ). The splittings of the signals a and $\mathrm{c}$ are more clearly discernible than those for polymer 2. Similar splittings of the signals were observed in the ${ }^{13} \mathrm{C}$ NMR spectra of the polymers derived from racemic 6,8-dioxabicyclo[3.2.1 octane $^{15}$ and its 4(e)-bromo- ${ }^{16}$ and 3(a),4(a)dibenzyloxy derivatives, ${ }^{4}$ but not in the spectra of the optically active polymers. ${ }^{17.18}$ The splittings were therefore ascribed to the diad tacticities of the D,L-enantiomeric monomeric units in the polymer chains; that is, the higher field peak of each signal pair was assigned to the corresponding carbon signal of the isotactic diads (D-D and $\mathrm{L}-\mathrm{L}$ consecutive units) and the lower field peak to that of the syndiotactic diads (D-L and L-D units). ${ }^{15,16} \mathrm{At}$ present, definite assignments of the split signals in the ${ }^{13} \mathrm{C}$ NMR spectrum of 3 cannot be made, since the chemical shift data for the corresponding optically active polymer are unavailable. However, by analogy of the assignments of the signals of the polymers of the parent bicyclic acetal and its 4(e)bromo derivative, it seems highly probable that the higher field peaks of the signal pairs a and $\mathrm{c}$ are due to the respective carbons of the isotactic diads and the lower field peaks to those of the syndiotactic diads. On the basis of these assignments, the isotactic diad fraction of polymer 3 was estimated to be 0.70 from relative peak intensities.

The synthetic polysaccharide 3 (3,4-dideoxy$(1 \rightarrow 6)-\alpha$-DL-thereo-hexopyranan) was obtained as a fluffy solid melting at $136-150^{\circ} \mathrm{C}$. It was soluble in methanol, dimethyl sulfoxide, and dimethylformamide, and insoluble in water as well as in other common organic solvents. Elemental analytical data were in good agreement with the calculated

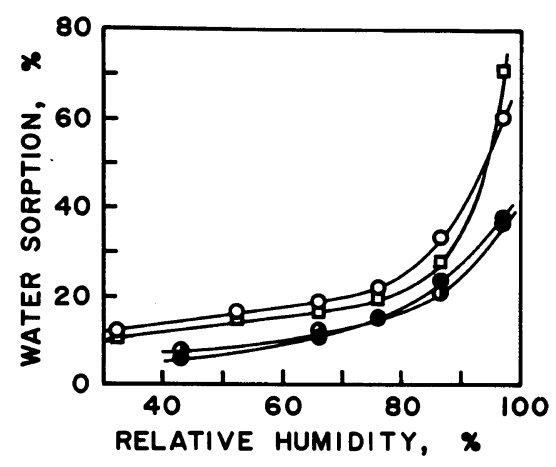

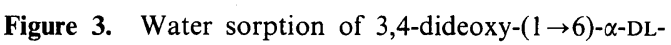
threo-hexopyranan (3) and its related polysaccharides at $25^{\circ} \mathrm{C}$ : $O$, dextran, $M_{n}=3.5 \times 10^{3} ; \square$, 4-deoxy- $(1 \rightarrow 6)-\alpha-$ DL-xylo-hexopyranan, $M_{n}=7.9 \times 10^{3}$; $, 3,4$-dideoxy$(1 \rightarrow 6)$ - $\alpha$-DL-erythro-hexopyranan, $M_{n}=7.8 \times 10^{3} ; \boldsymbol{O}, \mathbf{3}$, $M_{n}=1.4 \times 10^{3}, 20^{\circ} \mathrm{C}$.

values (Calcd. for $\left(\mathrm{C}_{6} \mathrm{H}_{10} \mathrm{O}_{3}\right)_{n}: \mathrm{C}, 55.39 \% ; \mathrm{H}$, $7.57 \%$. Found: C, $55.57 \%$; H, $7.79 \%$ ).

The water sorption of $\mathbf{3}$ was measured at different relative humidities from 43 to $97 \%$. The results are graphically represented in Figure 3 along with the data for two other synthetic polysaccharides and natural dextran having identical backbone structures. The water sorption behavior of 3 was similar to that of 3,4-dideoxy-( $\rightarrow \rightarrow 6)$ - $\alpha$-DL-erythro-hexopyranan. ${ }^{3}$ In spite of the presence of only one hydroxyl group per repeating unit, the water sorption of $\mathbf{3}$ at a given relative humidity amounted to $50-70 \%$ that of natural dextran. In view of the fact that the water sorption of natural dextran is reduced by an increase in the crystallinity of the samples, ${ }^{19,20}$ the relatively high water sorption of 3 is, at least in part, ascribable to the structure composed of D,L-enantiomeric monomeric units. That is, the less ordered structure compared with that of dextran supresses intermolecular hydrogen bondings between the chains, thus making water molecules readily accessible to the hydrophilic portions of the polymer.

Acknowledgments. The present work was supported in part by a Grant-in-Aid for Scientific Research (No. 00547090) from the Ministry of Education, Science and Culture of Japan. We are indebted to Mr. T. Hirasawa for his assistance during the course of this experiment. 


\section{REFERENCES}

1. V. V. Korshak, O. P. Golova, V. A. Sergeev, N. A. Merlis, and R. Y. Schneer, Vysokmol. Soedin., 3, 477 (1961); Chem. Abstr., 56, 5830 (1962).

2. I. J. Goldstein and T. L. Hullar, Adv. Carbohyd. Chem., 21, 431 (1966).

3. M. Okada, H. Sumitomo, and K. Ogasawara, Polym. J., 14, 815 (1982).

4. M. Okada, H. Sumitomo, and Y. Hishida, Makromol. Chem., 184, 1823 (1983).

5. F. Sweet and R. K. Brown, Can. J. Chem., 46, 2289 (1968).

6. R. M. Strivastava and R. K. Brown, Can. J. Chem., 48, 830 (1970).

7. T. P. Murray, U. P. Singh, and R. K. Brown, Can. J. Chem., 49, 2132 (1972).

8. J. Pecka, J. Staněk, Jr., and M. Cěrny, Collect. Czech. Chem. Commun., 39, 1192 (1974).

9. P. J. Beynon, P. M. Collins, D. Gardiner, and W. G. Overend, Carbohydr. Res., 6, 431 (1968).

10. M. Miljkovic, M. Gligorijevic, and Miljkovic, J. Org.
Chem., 39, 2118 (1974).

11. E. J. Corey and C. U. Khim, J. Am. Chem. Soc., 94, 7586 (1972).

12. E. R. Ruckel and C. Schuerch, J. Org. Chem., 31, 2233 (1966).

13. J. Frechet and C. Schuerch, J. Am. Chem. Soc., 91, 1161 (1969).

14. K. Kobayashi and C. Schuerch, J. Polym. Sci., Polym. Chem. Ed., 15, 913 (1977).

15. M. Okada, H. Sumitomo, and H. Komada, Macromolecules, 12, 395 (1979).

16. M. Okada, H. Sumitomo, and A. Sumi, Macromolecules, 15, 1238 (1982).

17. H. Komada, M. Okada, and H. Sumitomo, Macromolecules, 12, 5 (1979).

18. M. Okada, H. Sumitomo, and A. Sumi, Polym. Bull., 7, 431 (1982).

19. N. W. Taylor, H. F. Zobel, N. N. Hellman, and F. R. Senti, J. Phys. Chem., 63, 599 (1959).

20. N. W. Taylor, J. E. Chuskey, and F. R. Senti, J. Phys. Chem., 65, 1810 (1961). 